Article

\title{
Discussion Network Activation: An Expanded Approach to Selective Exposure
}

\author{
Benjamin A. Lyons ${ }^{1,2}$ \\ ${ }^{1}$ Department of Communication, University of Utah, Salt Lake City, UT 84112, USA; E-Mail: benjamin.a.lyons@gmail.com \\ 2 Department of Politics, University of Exeter, Exeter, EX4 4RJ, UK
}

Submitted: 26 March 2019 | Accepted: 15 May 2019 | Published: 30 July 2019

\begin{abstract}
Studies of selective exposure have focused on use of traditional media sources. However, discussion networks are an integral part of individuals' information diets. This article extends the selective exposure literature by exploring the potential for networks to likewise be selectively accessed. A pre-registered experiment found that participants nominate denser, more ideologically coherent networks in response to congenial political news relative to uncongenial news, and express willingness to share it with more people. Analysis of open-ended data suggest shared political beliefs are more likely to motivate discussant selection in response to congenial, rather than uncongenial, news. Properties of networks generated in response to political and non-political news did not vary. These results provide nuance to our understanding of political information exposure.
\end{abstract}

\section{Keywords}

discussion networks; information seeking; polarization; selective exposure; social identity

\section{Issue}

This article is part of the issue "Selective Exposure in a Changing Political and Media Environment", edited by María Luisa Humanes (University Rey Juan Carlos, Spain).

(C) 2019 by the author; licensee Cogitatio (Lisbon, Portugal). This article is licensed under a Creative Commons Attribution 4.0 International License (CC BY).

\section{Introduction}

An established body of literature has grappled with the tendency of individuals to selectively expose themselves to pro-attitudinal information, focusing on media content (Stroud, 2011). As individuals interact with identitythreatening information (e.g., political topics), they engage in biased search, seeking out information that bolsters their group's positions (Stroud, 2011). Ultimately though, studies of this phenomenon have operationalized information seeking behavior in terms of media use, considering only the causes and consequences of exposure to mediated messages. However, discussion networks serve as essential sources in individuals' personalized information environments. Discussion networks are comprised of the set of all social contacts with which an individual discusses a range of issues, including but not limited to politics (Klofstad, McClurg, \& Rolfe, 2009). Researchers may have shied away from examining net- works as dependent variables in such studies of selective exposure because they are often thought of as static entities, of whose information individuals are passive recipients (lyengar \& Hahn, 2009, p. 21). However, recent studies in organizational behavior (Menon \& Smith, 2014; Smith, Menon, \& Thompson, 2012) have shown that the activated portions of much larger latent networks are indeed guided by context and psychological states. This opens networks up to be seen as the outcomes of partisan selective exposure.

This project explores the potential for subsets of an individual's discussion network to be selectively accessed as information sources, based on situational motivations or psychological states. One reason this selectivity is increasingly important to understand is in light of large proportions of the public using social networking sites, because these sites enable maintaining and accessing larger networks containing more weak ties (Ellison, Steinfield, \& Lampe, 2011). If individuals are able to 
choose from a broader range of contacts for discussion, there is more potential for situational selectivity driven by the characteristics of a given news story.

The approach undertaken here also adds nuance to existing discussion network research that has overlooked situational variation. Such outcomes would be relevant to democratic functioning, because certain policy issues or news story characteristics may encourage different approaches to network activation, and thus produce different provisions of socially mediated information. Extending the basic theory behind selective media exposure to this domain, the congeniality of an issue may drive individuals to seek additional opinions from a broader or narrower subset of their discussion contacts.

Using a pre-registered experiment, I show how issue congeniality can shape discussion network activation. These results should broaden how researchers conceptualize partisan selective exposure. As individuals increasingly maintain discussion contacts online, and partisan media choices proliferate online (e.g., Brady, Crockett, \& Van Bavel, 2019), the potential for selective network activation in response to political news warrants further attention.

\section{Theory}

\subsection{Selective Exposure: From Media to Discussion}

Research on selective exposure stretches back decades (Berelson, Gaudet, \& Lazarsfeld, 1944; Zillmann \& Bryant, 1985). In recent years, transformations in the media environment have reinvigorated work in the area, focusing on the effects of increased audience control and a fragmented media landscape (Bennett \& lyengar, 2008; Brundidge, 2010; lyengar \& Hahn, 2009; Stroud, 2011). However, findings about the potential for increasing selective exposure over time remain mixed (Guess, Nyhan, Lyons, \& Reifler, 2018).

Importantly, though, citizens consult sources other than news media when forming and reinforcing their understanding of the political world. Interpersonal discussion is an equally important component in the flow of political communication (Katz, 1957; McLeod, Scheufele, \& Moy, 1999; Moy \& Gastil, 2006). Discussion is in many ways aided by the current proliferation of social network sites, enabling consultation with a broader network containing more latent, weak ties (Ellison, Steinfield, \& Lampe, 2007). But just as importantly, individuals may exhibit partisan selectivity in accessing these other, nonnews sources as well. The key contribution of this article is addressing selectivity in the broader set of information channels citizens access. Specifically, this article addresses a form of second-step selectivity that occurs after media exposure, when media content is digested and reflected upon through discussion (Shah et al., 2017).

Researchers should include discussion networks in examinations of selectivity, then, because not only do they comprise one of the two key components of the polit- ical communication ecosystem, but because individuals think of partisan media and partisan group members in much the same way; both are seen through the same partisan lens (Stroud, Muddiman, \& Lee, 2014). In other words, media outlets and discussion partners are thought of (and potentially selected) in many of the same ways.

\subsection{Discussion Networks and Contextual Activation}

Interpersonal networks serve as critical sources of information, with both denser network structures, wherein more of the contacts know one another (i.e., network density; Granovetter, 1973) and greater similarity among members (i.e., network homogeneity; Huckfeldt, Mendez, \& Osborn, 2004) ultimately degrading information availability (Klar \& Shmargad, 2017) and quality of thought. Homogenous networks strengthen and even polarize concordant opinions, though these protected, affirming pockets of like-mindedness can instil more passion to participate in the political process. Disagreement within personal networks likely has several beneficial outcomes. It can increase tolerance by depolarizing feelings about in and out-groups (Parsons, 2010). Anticipation of future disagreement can drive an information search for new material (Eveland, 2004). It can increase knowledge and sophistication through increased exposure to diverse or novel information, and can in turn strengthen one's arguments. It increases understanding of both one's own position and the rationales supporting the opposition's. This can in turn lead to higher levels of persuasion (Barabas, 2004; Gastil \& Dillard, 1999; Huckfeldt et al., 2004; Levitan \& Visser, 2008; Mutz, 2002; Scheufele, Nisbet, Brossard, \& Nisbet, 2004).

Although networks are conceptually recognized as dynamic phenomena, most studies measure their composition and antecedents as static (Klein, Saltz, \& Mayer, 2004; McPherson, Smith-Lovin, \& Brashears, 2006; Sasovova, Mehra, Borgatti, \& Schippers, 2010). Instead of consistently activating the same discussants in every context, however, individuals seek different components of their far-larger latent network based on conscious or unconscious motivations (Menon \& Smith, 2014). Because individuals' sense of who they are shifts situationally (for example, when their partisan identity is threatened by uncongenial information), "so too does their mental representation of their social networks," (Menon \& Smith, 2014, p. 117; Smith et al., 2012). Rather than being strategic in network activation, Menon and Smith (2014) argue that patterns of activation depend on underlying psychological states. The congeniality of a media message may alter these states (Hasell \& Weeks, 2016).

\subsection{News Content's Potential to Shape Network Activation}

It has long been acknowledged that information flows from mass media through media audiences and on to interpersonal discussion networks (Katz, 1957). The ar- 
gument made here is that it does so differentially based on media content. Individuals not only selectively share which content to consume based on valence, but subsequently selectively choose who to discuss it with based on its valence.

Given media that is congenial or uncongenial to one's views, how does the second step of flow proceedthrough congenial or uncongenial discussion partners? Some prior work suggests congenial political news might be discussed more often with co-partisans. Individuals may seek to strengthen bonds with those with whom they already consistently agree (Ellison et al., 2007). In complementary fashion, news consumers may share uncongenial news with dissimilar discussants in an effort to cater to that discussant's tastes (Atkin, 1972; Lerner \& Tetlock, 1999).

However, other work that examines news sharing and proselytizing behaviors could suggest the oppositethat individuals would be more likely to discuss news casting their preferred party in a flattering light more broadly overall, and more frequently with out-partisans, specifically. One reason for this may be schadenfreude, or happiness at the misfortune of others. Some news consumers may look to spread news of a politician's embarrassment to gloat in the face of their out-party social contacts (Crysel \& Webster, 2018). Another reason individuals may share news they find congenial with out-partisans is with aim of persuading them (Thorson, 2014). Congenial news may be seen as potentially persuasive ammunition in ongoing deliberations among social contacts with discordant views. This is supported by evidence that cable news viewers-who are more likely to see likeminded content-proselytize more often than other news viewers (Platzman, 2015).

\section{Hypotheses and Research Questions}

Do individuals nominate more or less ideologically homogenous discussion networks, or more or less dense networks, based on the political congeniality of the news article? Do these network characteristics vary between political and non-political issue cues? This study compares discussion network activation for a variety of topics, using a pre-registered experiment (see osf.io/2xv9q/ ?view_only=9005ea7a577443f797a962edeedca7a2 for hypotheses, questionnaire, stimuli, and analysis plan). I test two key aspects of news that might drive echo chamber dynamics: attitudinal congeniality and political vs non-political content.

First, I examine response to pro- and counterattitudinal fact-checks of Donald Trump. Some research suggests that pro-attitudinal news is more likely to be discussed with one's in-group to stimulate bonding (Ellison et al., 2007). However, studies on selective sharing (An, Quercia, \& Crowcroft, 2014; Aruguete \& Calvo, 2018), particularly regarding congenial and uncongenial factchecks (Shin \& Thorson, 2017), suggest that individuals will be more likely to discuss "good news," (rather than "bad news") about their party with the other side, whether to persuade or to gloat and self-gratify (Crysel \& Webster, 2018).

H1. Pro-attitudinal fact-checks will produce less dense, less politically homogenous network subsets than counter-attitudinal fact-checks.

I then examine response to three non-political topics. These comprise two hard news and one soft news topic, with hard news varying in its degree of controversyvaccine hesitancy, self-driving cars, and popular films. I expect political views will not motivate network activation for these issues. It's less clear how the density of networks might be affected. The literature is unclear as to whether political or non-political topics will produce denser networks. I also check for any key differences amongst the set of non-political topics.

H2. Non-political issues will produce less politically homogenous networks than political issues.

RQ1. Is there any difference in the density of networks produced by political and non-political issue cues? RQ2. Do non-political topics' networks differ from one another in density or homogeneity?

Prior to the network properties I analyse, I first ask a basic "reach" question-how widely would you share this news? I expect pro-attitudinal news will have greater reach than counter attitudinal news. I am agnostic about any other differences in this outcome.

H3. Pro-attitudinal fact-checks will have greater reach than counter-attitudinal fact-checks.

\subsection{Planned Exploratory Analyses}

Finally, I include an open-ended prompt for participants to describe their selection motivations in their own words. I later present these responses in an exploratory analysis. I also conduct exploratory tests of the moderating roles of political interest and strength of partisanship.

\section{Methods}

\subsection{Sample and Design}

Participants ( $N=1,872$ ) were recruited through Amazon Mechanical Turk in February 2019. They were paid $\$ .90$ and completed the experiment in an average of $4.80 \mathrm{~min}-$ utes $(S D=4.54)$. Participants were $55.65 \%$ male, $79.5 \%$ white, with a mean age of $36.76(S D=11.27)$, and median education of a bachelor's degree. Including "leaners," 56.3\% were Democrats, 32.26\% were Republicans, and $11.45 \%$ were independents. In terms of Trump support, 34.83\% supported him "somewhat" or "strongly".

They first provided demographic information before being randomly assigned to view the headline and pre- 
view image for one of seven news articles. These articles included four fact-checks of Donald Trump drawn from Politifact-two with "True" ratings and two with "False" ratings, and three non-political news articles, also drawn from real sources, concerning self-driving car safety (from The Telegraph), the dangers of the antivaccination movement (from The Independent), and the 50 best comedies of the century (from Rolling Stone). They were then asked a series of questions about with whom they would discuss the news story, which served as outcome measures.

\subsection{Measures}

\subsubsection{Independent Variables}

For those exposed to a fact-check article, congeniality is calculated by taking the slant of article (Trump "True" statements are Pro-Republican, Trump "False" statements are Pro-Democrat) crossed with respondent party (Republican/Democrat), resulting in scores of -1 (uncongenial, $\mathrm{N}=485$ ) or 1 (congenial, $\mathrm{N}=456$ ). Because I am interested in the effects of congeniality, I do not include Independents in these analyses. I conduct supplementary analyses in which they are included. I also conduct a robustness check in which I substitute Trump support in the place of party in the congeniality calculation (Trump support is 4-pt., centered: $-2,-1,1,2$, and crossed with slant). Other indicator variables were constructed using treatment assignment (i.e., a "Vaccines" indicator, a "Self-driving cars" indicator, and a "Movies" indicator based on assignment to these articles).

\subsubsection{Dependent Variables}

Reach $(M=1.11, S D=.92)$ was gauged by asking "How many people would you share this news with?" (4 pt., $0=$ "none," 3 = "a lot.").

Cognitive network activation was again gauged using measures drawing on the GSS network battery. Participants were asked to provide up to 5 discussion partners, the strength of ties among these $(0,1,2)$, the political ideology of each ( 1 = very liberal, $7=$ very conservative), and the party affiliation of each (Democrat, Republican, something else).

Network density is again calculated by summing the strength of ties and dividing by total possible ties of each respondent's network. The resulting measure $(M=2.27$, $\mathrm{SD}=.60$ ) ranged from 1 to 3 .

Network homogeneity (Makse \& Sokhey, 2014) takes the average of the alters' party affiliation agreement with respondent party (e.g., when respondent is Republican and alter is Republican $=1$, when alter is Democrat or other $=0)$. The average $(M=.56, S D=.41)$ thus ranges from 0 to 1 . As an alternate measure of homogeneity, I measure network coherence. In all hypotheses regarding network homogeneity, I refer to both measures. For network coherence (Erisen \& Erisen, 2012),
I use reported ideology of each contact measured on a 1-7 scale, and the participant's self-reported ideology from the same scale. I then take the absolute value of the ideological distance between the participant and each contact and average the distances to find the political coherence of the network from the perspective of the participant. Coherence $(M=1.32, S D=1.09)$ ranges from 0 to 6 . To aid in interpretation, I multiply coherence by -1 , so that participants with more ideologically similar alters score higher.

\subsubsection{Moderators}

Strength of partisanship ( $1=$ strong, $M=.42, S D=.49$ ), and political interest (5 pt., $5=$ "very interested," $\mathrm{M}=3.32, \mathrm{SD}=1.08$ ) were measured as potential moderating variables.

\section{Results}

\subsection{Congeniality Effects on Network Properties}

All analyses were conducted using OLS regression. H1 stated that pro-attitudinal fact-checks would produce less dense, less politically homogenous network subsets than counter-attitudinal fact-checks. Accordingly, I fit a series of OLS regressions, one for each of the three network properties, with congeniality as the independent variable. These models include all participants who were assigned to one of the political (fact-check) conditions. Additionally, as the focus is on network properties, only participants who provided more than 1 alter could be included. 225 partisans said they would discuss the news with 1 or 0 others and were thus excluded from these network property models. The results are depicted in Figure 1. Congenial news exposure produced denser discussion networks $(b=.05, p=.028)$, and networks that were more coherent-or ideologically similar to the participant ( $b=.10, p=.008)$. There was no effect on the measure of network homogeneity derived from binary partisanship $(b=.01, p=.316)$. All analyses were robust to the inclusion of question fixed effects to account for specific article assignment.

\subsection{Political vs. Non-Political News Effects on Network Properties}

$H 2$ stated that non-political issues would produce less politically homogenous networks than political issues. $R Q 1$ asked if there are there any differences in the density of networks produced by political and nonpolitical issue cues. These models include the article-assignment indicator variables-vaccines, self-driving cars, and moviesas independent variables. The fact-check conditions are left out as the reference category. Results show no significant differences in network properties between political and non-political content. $R Q 2$ asked if non-political topics' networks differ from one another in density or 


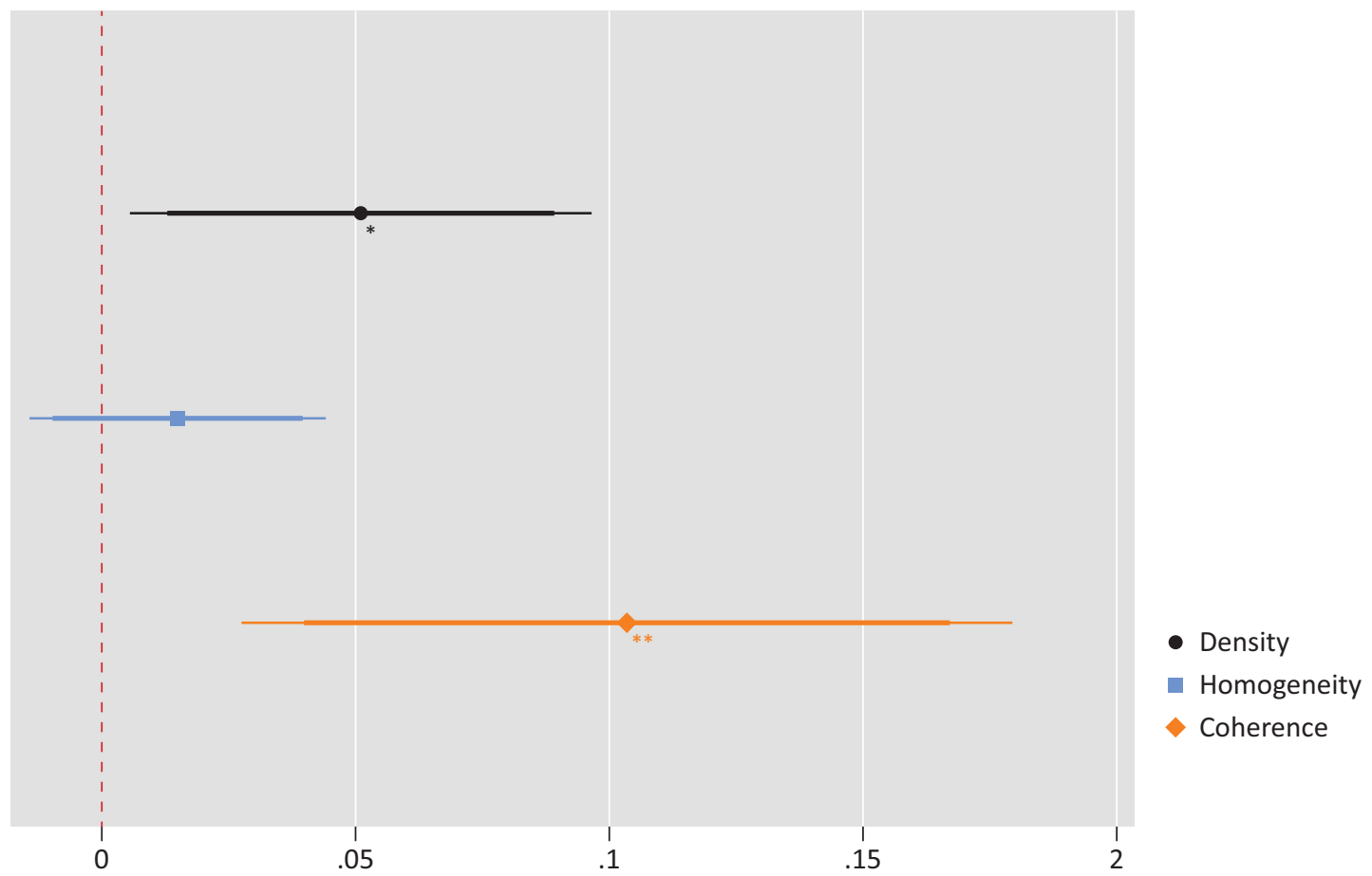

News Congeniality Effects on Discussion Network Properties

Figure 1. News congeniality effects on discussion network properties. Notes: network density is based on the average strength of ties among all alters $(\mathrm{N}=661)$. Network homogeneity is based on shared partisan affiliation between participants and alters $(N=786)$. Network coherence is based on average ideological distance of alters from the participant $(\mathrm{N}=786)$.

homogeneity. Models addressing this question included all participants assigned to non-political stimuli, with the "movies" article left out as the reference category. Again, there were no significant differences across nonpolitical content.

\subsection{Effects on Reach}

H3 stated that pro-attitudinal fact-checks would have greater reach than counter-attitudinal fact-checks. To address this question, the previous model restriction to participants providing at least 2 alters was lifted. Participants reported intention to share pro-attitudinal news more widely, $b=.08, p=.008$. However, all non-political news stories (vaccines, $b=.46, p<.001$, self-driving cars, $b=.27, p<.001$, and movies, $b=.24, p<.001)$ generated greater willingness to share more widely than did political stories, as shown in Figure 2.

\subsection{Exploratory Analyses}

Planned exploratory analysis of political interest's potential moderating role was conducted using OLS regression, replicating the models used to test $H 1$, with the addition of the moderating variable and the interaction term of interest and congeniality. Results show political interest moderated the effect of congeniality on network homogeneity and network coherence such that congeniality's effect on these was greater among high-interest partisans and lesser among low-interest partisans. There was no interaction in the density model. The congenialityinterest interactions are depicted in Figure 3. The same tests were conducted using strength of partisanship in the place of interest. There were no significant interactions, though the effects of congeniality were robust to the inclusion of strength of partisanship in the model.

I also conducted two planned robustness tests (one additional planned robustness test, in which trait network similarity would be included as a covariate, was not conducted as the measure was not included in the online questionnaire in error). First, Trump support was used in the place of partisanship in construction of the congeniality indicator. The results were substantively similar. Using the Trump-support congeniality indicator, proattitudinal news still produced denser networks $(b=.04$, $p=.005)$, had no effect on homogeneity $(b=.00$, $p=.674)$, produced more ideologically coherent networks (though the effect was weaker, $b=.04, p=.073$ ), and generated greater reach $(b=.04, p=.020)$. Next, because the research was motivated by questions of selective exposure, only partisans were included in the above analyses. Separate analyses were conducted using the full sample, including independents. These models produced substantively identical results.

Finally, I conducted an exploratory analysis of openended responses concerning selection motivation. This 


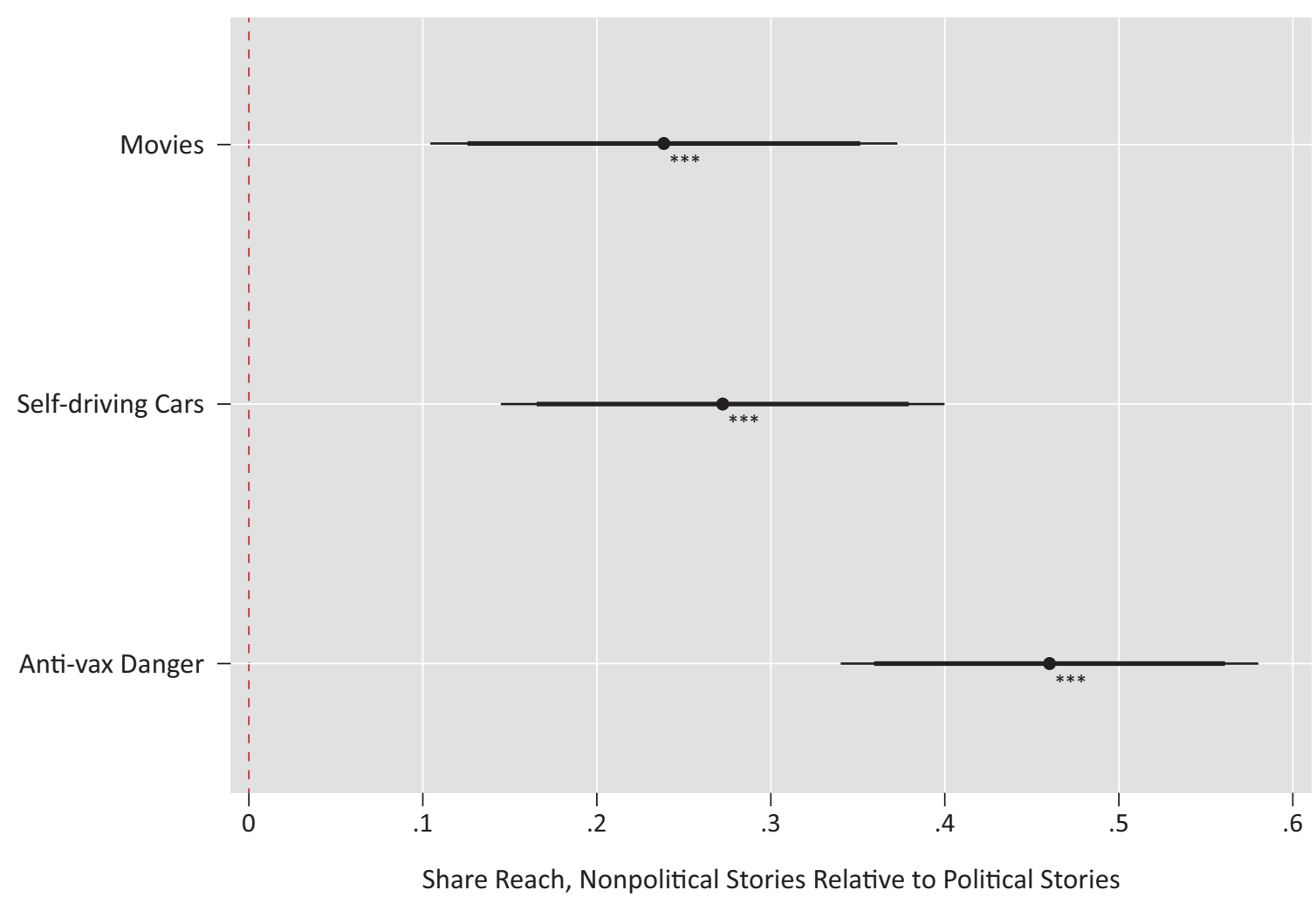

Figure 2. Share reach of non-political stories relative to political stories. Notes: share reach measured as "How many people would you share this news with?" (4 pt., $0=$ "none", 3 = "a lot."). $N=1,872$.

Conditional Marginal Effects of Congeniality Across Interest, with 95\% Cls
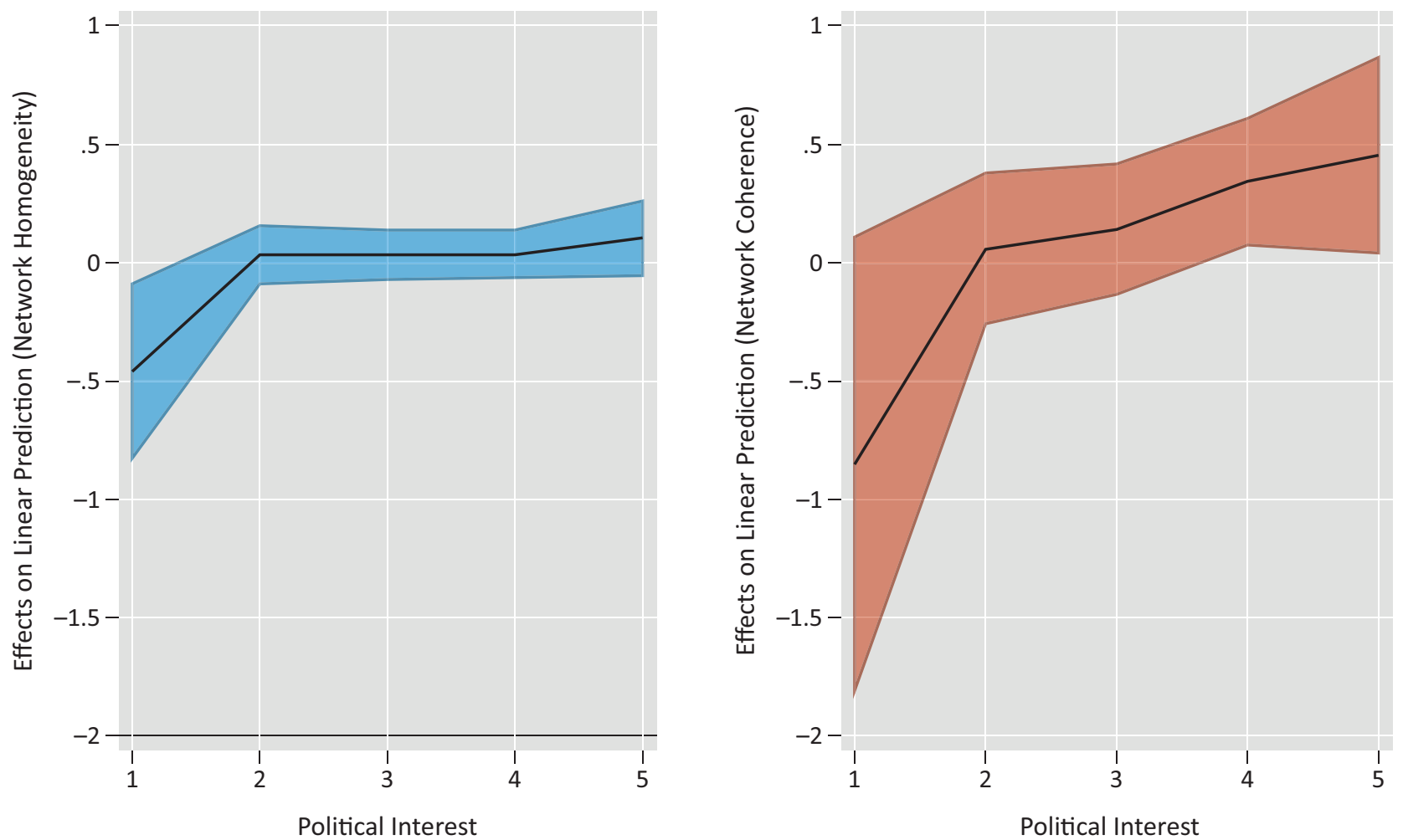

Figure 3. News congeniality effect on network homogeneity and coherence, across political interest. Notes: network homogeneity is based on shared partisan affiliation between participants and alters. Network coherence is based on average ideological distance of a network from the participant. Both $\mathrm{N}=786$. 
analysis focused on partisans in the political news conditions in order to examine potential differences driven by congeniality ( $N=941$; after filtering for $N / A$ responses, $\mathrm{N}=821$ ). An initial assessment of the responses suggested the 11 motivations depicted in Table 1. Many respondents said discussants were chosen because they were close friends and family $(\mathrm{N}=265)$ or habitual political discussants $(\mathrm{N}=135)$, or they were generally comfortable discussing politics with the discussant $(\mathrm{N}=70)$. Many respondents also said they chose no one because they don't discuss politics in general $(N=90)$. Still, a good number of respondents indicated that their selections were based on more situational factors. Logistic regression models predicting each motivation by the news article's congeniality show that those exposed to congenial news were more likely to select discussants based on shared political views $(O R=1.33, p=.022)$. On the other hand, those exposed to congenial content were less likely to say they selected "no discussant" due to content-specific reasons (those exposed to uncongenial news were more likely to do so) ( $O R=.77, p=.021)$. Those expressing this motivation often doubted the veracity of the uncongenial news item (e.g., "fake news").

\section{Discussion}

This study found that participants nominate denser and more cohesive sets of discussion partners in response to pro-attitudinal news, or conversely, that counterattitudinal news may be shared with more diverse subsets. In other words, at least regarding news centering on claims made by Trump, individuals appear to be more eager to share pro-attitudinal news with co-partisans, particularly those in their inner circle. Notably, this finding is the opposite of the hypothesized effect of congeniality. One potential account for these results is that participants are not interested in persuading out-party members with news that may disconfirm their prior be- liefs, but instead looking to reinforce bonds over agreeable news stories with those with whom they already know they agree (Ellison et al., 2007). And on the other hand, readers may choose to discuss counter-attitudinal news more broadly in an effort to cater to those (moredistant) audiences' differing tastes (Lerner \& Tetlock, 1999). More broadly, readers are more likely to attend to news with cues that others will be interested; there is a social utility gratification of the information (Atkin, 1972). Therefore, social utility may help explain the results. These accounts, especially the former, are somewhat supported in the open-ended data.

Notably, though, participants reported interest in sharing pro-attitudinal news with more people. Differential effects of political versus non-political content on network properties were limited, but participants reported willingness to share non-political content more widely overall. When given the option, most people prefer to opt out of political news (Guess et al., 2018). Finally, I find that political interest moderates the effects of congeniality such that more interested partisans nominate denser, more cohesive networks in response to pro-attitudinal content, while those low in interest nominate broader, less ideologically coherent networks in response. In each case, these finding track with evidence on the greater prevalence of echo chambers among the most highly engaged partisans (Guess et al., 2018).

The study also has important limitations. This study's political news stimuli center on President Trump, which might uniquely shape discussion, even relative to other affect-laden political content. Still, the stimuli are an accurate representation of contemporaneous political discussion topics; veracity of claims made by polarizing politicians on the national stage are now a centerpiece of public discourse. Moreover, it is important to note that this study cannot ascertain the quality, diversity, or depth of the conversation yielded by differential degrees of density or homogeneity in the respondents' networks.

Table 1. Open-ended responses for network selection motivations as predicted by news congeniality.

\begin{tabular}{lcccc}
\hline Motivation & Uncongenial & Congenial & Total & $\begin{array}{c}\text { Congeniality regression } \\
\text { Odds ratio }\end{array}$ \\
\hline Close friend/family & 131 & 134 & 265 & $1.04(.08)$ \\
Habitual political discussant & 58 & 77 & 135 & $1.20(.11)$ \\
Comfort with discussant & 38 & 32 & 70 & $.92(.12)$ \\
Expertise & 15 & 17 & 32 & $1.08(.20)$ \\
Interest to discussant & 38 & 31 & 69 & $.91(.11)$ \\
Diverse views & 17 & 10 & 27 & $.77(.16)$ \\
Shared beliefs & 28 & 46 & 74 & $1.33(.17)^{*}$ \\
No one-no political discussion & 14 & 12 & 26 & $.94(.19)$ \\
No one-not this topic & 56 & 34 & 90 & $.77(.09)^{*}$ \\
Inform/persuade & 4 & 6 & 10 & $1.24(.40)$ \\
Other & 17 & 6 & 23 & 821 \\
\hline Total & 416 & 405 &
\end{tabular}

Notes: ${ }^{*}=p<.05 . \mathrm{N}=821$. Column $2-4$ : frequencies. Column 5: odds ratio for congeniality predicting each motivation based on logistic regression. 
However, overall, these findings help establish that news topics shape discussion networks.

\section{Conclusion: Understanding Information Processes in a Socially Mediated Age}

These results show that accessing networks is often situationally contingent (though this may be either strategic or subconscious). Hence, a discussion network may sometimes serve as an echo chamber and sometimes as a more diverse source. Studies using a single-shot self-reported network item, or constructing a network from trace data, may elide the fact that only certain subsets are activated for different discussions and this varies with social and informational cues. These findings suggest that discussion networks are endogenous to media use and not simply a static, independent factor moderating its effects on attitudes, knowledge, and other behavior. Building on these findings, selective exposure models should incorporate both discussion and media use, examining their interplay through a reinforcing spirals framework (Slater, 2007).

For this reason, there are unique implications of contextual network activation for affective polarization and knowledge. Contextually activated discussion networks are consequential for the person processing the news, but also for his or her alters-both in their exposure to information and in the social conditions under which they are exposed (Druckman, Levendusky, \& McLain, 2018). Indeed, partisans may selectively discuss political content with others, but this should not be understood as a one-way street of selectivity. Partisans are selectively exposing themselves and others to congenial responses when they choose to "share."

The fact that political talk is a two-way streetwherein individuals activate contacts to seek their opinions but also to shape them-warrants more attention in future research. The current work cannot interrogate these processes, instead only seeking to establish that political discussion unfolds in a manner compatible with the tenets of selective exposure. However, additional studies may examine the effects of selective network activation, in terms of the quality and diversity of information that is ultimately accessed, and the downstream effects of this selective two-step flow on those not directly exposed to a given media message (e.g., Aruguete, \& Calvo, 2018; Carlson, 2018; Druckman et al., 2018).

Further, future work should examine the effects of homogenous social settings (e.g., if an individual is embedded in a partisan echo chamber in their social network platform of choice), which may make group threats more salient and drive activation of network contacts accordingly. Conversely, a social setting that provides reminders of an individual's wide variety of social circles may spur contact with a more diverse set of discussants. Examining these questions of social context matter because news exposure is socially embedded (Ahmadi \& Wohn, 2018; Barnidge, 2017; Lee \& Kim, 2017).
This study was largely exploratory, examining whether content cues would shape networks. Replications and extensions are needed. However, they provide a basis from which considering discussion network activation and taking seriously the role of cues and motivations will enrich our understanding of how citizens (selectively) engage with the political world.

\section{Acknowledgments}

The author would like to thank Jason Reifler for feedback on the current iteration, and Aaron Veenstra and Scott McClurg for feedback on prior versions of the project. This project has received funding from the European Research Council (ERC) under the European Union's Horizon 2020 research and innovation programme [grant agreement number 682785].

\section{Conflict of Interests}

The author declares no conflict of interests.

\section{References}

Ahmadi, M., \& Wohn, D. Y. (2018). The antecedents of incidental news exposure on social media. Social Media + Society, 4(2), 1-8. https://doi.org/10.1177/ 2056305118772827

An, J., Quercia, D., \& Crowcroft, J. (2014). Partisan sharing: Facebook evidence and societal consequences. In Proceedings of the second ACM conference on online social networks (pp. 13-24). New York, NY: ACM.

Aruguete, N., \& Calvo, E. (2018). Time to \#protest: Selective exposure, cascading activation, and framing in social media. Journal of Communication, 68(3), 480-502.

Atkin, C. K. (1972). Anticipated communication and mass media information-seeking. Public Opinion Quarterly, 36(2), 188-199.

Barabas, J. (2004). How deliberation affects policy opinions. American Political Science Review, 98(4), 687-701.

Barnidge, M. (2017). Exposure to political disagreement in social media versus face-to-face and anonymous online settings. Political Communication, 34(2), 302-321.

Bennett, W. L., \& lyengar, S. (2008). A new era of minimal effects? The changing foundations of political communication. Journal of Communication, 58(4), 707-731.

Berelson, B., Gaudet, H., \& Lazarsfeld, P. F. (1944). The people's choice: How the voter makes up his mind in a presidential campaign. New York, NY: Columbia University Press.

Brady, W. J., Crockett, M., \& Van Bavel, J. J. (2019). The MAD model of moral contagion: The role of motivation, attention and design in the spread of moralized content online. PsyArXiv. Retrieved from https:// 
psyarxiv.com/pz9g6

Brundidge, J. (2010). Encountering "difference" in the contemporary public sphere: The contribution of the Internet to the heterogeneity of political discussion networks. Journal of Communication, 60(4), 680-700.

Carlson, T. N. (2018). Modeling political information transmission as a game of telephone. The Journal of Politics, 80(1), 348-352.

Crysel, L. C., \& Webster, G. D. (2018). Schadenfreude and the spread of political misfortune. PloS one, 13(9), 1-27. https://doi.org/10.1371/journal. pone.0201754

Druckman, J. N., Levendusky, M. S., \& McLain, A. (2018). No need to watch: How the effects of partisan media can spread via interpersonal discussions. American Journal of Political Science, 62(1), 99-112.

Ellison, N. B., Steinfield, C., \& Lampe, C. (2007). The benefits of Facebook "friends": Social capital and college students' use of online social network sites. Journal of Computer-Mediated Communication, 12(4), 1143-1168.

Ellison, N. B., Steinfield, C., \& Lampe, C. (2011). Connection strategies: Social capital implications of Facebook-enabled communication practices. New Media \& Society, 13(6), 873-892.

Erisen, E., \& Erisen, C. (2012). The effect of social networks on the quality of political thinking. Political Psychology, 33(6), 839-865.

Eveland, W. P. (2004). The effect of political discussion in producing informed citizens: The roles of information, motivation, and elaboration. Political Communication, 21(2), 177-193.

Gastil, J., \& Dillard, J. P. (1999). Increasing political sophistication through public deliberation. Political Communication, 16(1), 3-23.

Granovetter, M. S. (1973). The strength of weak ties. American Journal of Sociology, 78(6), 1360-1380.

Guess, A., Nyhan, B., Lyons, B., \& Reifler, J. (2018). Avoiding the echo chamber about echo chambers: Why selective exposure to like-minded political news is less prevalent than you think. Miami, FL: Knight Foundation.

Hasell, A., \& Weeks, B. E. (2016). Partisan provocation: The role of partisan news use and emotional responses in political information sharing in social media. Human Communication Research, 42(4), 641-661.

Huckfeldt, R., Mendez, J. M., \& Osborn, T. (2004). Disagreement, ambivalence, and engagement: The political consequences of heterogeneous networks. Political Psychology, 25(1), 65-95.

lyengar, S., \& Hahn, K. S. (2009). Red media, blue media: Evidence of ideological selectivity in media use. Journal of Communication, 59(1), 19-39.

Katz, E. (1957). The two-step flow of communication: An up-to-date report on an hypothesis. Public Opinion Quarterly, 21(1), 61-78.
Klar, S., \& Shmargad, Y. (2017). The effect of network structure on preference formation. The Journal of Politics, 79(2), 717-721.

Klein, K. J., Saltz, J. L., \& Mayer, D. M. (2004). How do they get there? An examination of the antecedents of centrality in team networks. Academy of Management Journal, 47(6), 952-963.

Klofstad, C. A., McClurg, S. D., \& Rolfe, M. (2009). Measurement of political discussion networks: A comparison of two "name generator" procedures. Public Opinion Quarterly, 73(3), 462-483.

Lee, J. K., \& Kim, E. (2017). Incidental exposure to news: Predictors in the social media setting and effects on information gain online. Computers in Human Behavior, 75, 1008-1015.

Lerner, J. S., \& Tetlock, P. E. (1999). Accounting for the effects of accountability. Psychological Bulletin, 125(2), 255.

Levitan, L. C., \& Visser, P. S. (2008). The impact of the social context on resistance to persuasion: Effortful versus effortless responses to counter-attitudinal information. Journal of Experimental Social Psychology, 44(3), 640-649.

Makse, T., \& Sokhey, A. E. (2014). The displaying of yard signs as a form of political participation. Political Behavior, 36(1), 189-213.

McLeod, J. M., Scheufele, D. A., \& Moy, P. (1999). Community, communication, and participation: The role of mass media and interpersonal discussion in local political participation. Political Communication, 16(3), 315-336.

McPherson, M., Smith-Lovin, L., \& Brashears, M. (2006). Social isolation in America: Changes in core discussion networks over two decades. American Sociological Review, 71(3), 353-375.

Menon, T., \& Smith, E. B. (2014). Identities in flux: Cognitive network activation in times of change. Social Science Research, 45, 117-130.

Moy, P., \& Gastil, J. (2006). Predicting deliberative conversation: The impact of discussion networks, media use, and political cognitions. Political Communication, 23(4), 443-460.

Mutz, D. C. (2002). Cross-cutting social networks: Testing democratic theory in practice. American Political Science Review, 96(1), 111-126.

Parsons, B. M. (2010). Social networks and the affective impact of political disagreement. Political Behavior, 32(2), 181-204.

Platzman, P. (2015). American partisan media consumption and voting persuasion attempts: How 24-hour cable news incites political proselytizing. SSRN. Retrieved from https://papers.ssrn.com/sol3/papers. cfm?abstract_id $=2953698$

Sasovova, Z., Mehra, A., Borgatti, S. P., \& Schippers, M. C. (2010). Network churn: The effects of self-monitoring personality on brokerage dynamics. Administrative Science Quarterly, 55(4), 639-670.

Scheufele, D. A., Nisbet, M. C., Brossard, D., \& Nisbet, 
E. C. (2004). Social structure and citizenship: Examining the impacts of social setting, network heterogeneity, and informational variables on political participation. Political Communication, 21(3), 315-338.

Shah, D. V., McLeod, D. M., Rojas, H., Cho, J., Wagner, M. W., \& Friedland, L. A. (2017). Revising the communication mediation model for a new political communication ecology. Human Communication Research, 43(4), 491-504.

Shin, J., \& Thorson, K. (2017). Partisan selective sharing: The biased diffusion of fact-checking messages on social media. Journal of Communication, 67(2), 233-255.

Slater, M. D. (2007). Reinforcing spirals: The mutual influence of media selectivity and media effects and their impact on individual behavior and social identity. Communication Theory, 17(3), 281-303.
Smith, E. B., Menon, T., \& Thompson, L. (2012). Status differences in the cognitive activation of social networks. Organization Science, 23(1), 67-82.

Stroud, N. J. (2011). Niche news: The politics of news choice. Oxford: Oxford University Press.

Stroud, N. J., Muddiman, A., \& Lee, J. K. (2014). Seeing media as group members: An evaluation of partisan bias perceptions. Journal of Communication, 64(5), 874-894.

Thorson, E. (2014). Beyond opinion leaders: How attempts to persuade foster political awareness and campaign learning. Communication Research, 41(3), 353-374.

Zillmann, D., \& Bryant, J. (1985). Affect, mood, and emotion as determinants of selective exposure. Selective Exposure to Communication, 1985, 157-190.

\section{About the Author}

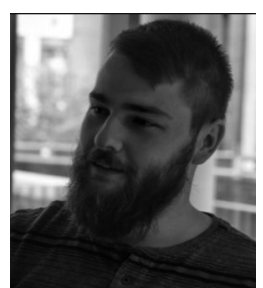

Benjamin A. Lyons is an Assistant Professor of Science, Environment, and Risk Communication in the Department of Communication at the University of Utah, and a Research Fellow in the Department of Politics at the University of Exeter. His work examines how people encounter and interpret information, and how social or technological contexts influence these processes. 